\section{Bias der Messung}

C. Vidal ${ }^{1}$ und W.-R. Külpmann ${ }^{2}$

${ }^{1}$ Landeskriminalamt Niedersachsen, Dezernat 53 „Chemie“, Hannover, Deutschland

${ }^{2}$ Hannover, Deutschland

Englischer Begriff measurement bias; bias
Definition Schätzwert einer systematischen Messabweichung (BIPM et al. 2010). Für Anmerkungen s. Literatur.

\section{Literatur}

BIPM, IEC, IFCC, ILAC, ISO, IUPAC, IUPAP, OIML (2010) Internationales Wörterbuch der Metrologie (VIM). Deutsch-englische Fassung. ISO/IEC-Leitfaden 99:2007, 3. Aufl. Beuth-Verlag, Berlin 